\title{
ONTOLOGICAL SECURITY OF AN INDIVIDUAL: ATTACHMENT STYLES AND COPING STRATEGIES
}

\author{
NADIYA HAPON \\ Ivan Franko National University of Lviv \\ Faculty of Philosophy, Department of Psychology \\ Universytetska 1, Lviv, 79000 Ukraine \\ E-mail address: Nadiya.Hapon@lnu.edu.ua \\ ORCID https://orcid.org/0000-0002-8699-2420 \\ ANNA VOVK \\ Ivan Franko National University of Lviv \\ Faculty of Philosophy, Department of Psychology \\ Universytetska 1, Lviv, 79000 Ukraine \\ E-mail address: Anna.Vovk@1nu.edu.ua \\ ORCID https:/ / orcid.org/0000-0003-1505-7096
}

\section{IRYNA SNYADANKO}

Lviv Polytechnic National University

Institute of Jurisprudence, Psychology and Innovative Education

Department of Theoretical and Applied Psychology

Kniazia Romana 1-3, Lviv, 79000 Ukraine

E-mail address: snjadanko8@gmail.com

ORCID https://orcid.org/0000-0003-4245-1443

\section{LILIYA FEDYNA}

Faculty of Philosophy, Department of Psychology

Universytetska 1, Lviv, 79000 Ukraine

E-mail address: 1.ivaniv5@ukr. Net

ORCID https://orcid.org/0000-0001-7285-5313

\begin{abstract}
Aim. The aim of this paper is to theoretically substantiate individual's attachment as a need for ontological security, to outline the educational aspects of supporting the ontological security, and to empirically investigate the attachment styles and coping strategies of individuals in early and middle adulthood.

Methods. The article is based on an extensive review of the literature, which involves the use of such methods as interpretation (of previously unexplained psycho-
\end{abstract}


logical aspects of ontological security) and comparative analysis (of the views of Ronald Laing and family psychotherapists). An empirical study was conducted. The study group consisted of 90 persons: 45 male and 45 female, at the age of early and middle adulthood. The research used a number of psychological methods to study different types of attachments, relationships, personality traits and coping strategies that help overcome ontological insecurity. The method of statistical and mathematical analysis of results was also applied.

Results. Ontological security is a marker of positive types of attachment. Our empirical research has shown that people with anxious attachment more often overcome ontological insecurity by positively rethinking the problem, which can lead to an underestimation of the possibilities of its effective solution. People with a reliable attachment are ontologically secure due to mutual trust, responsibility, problem analysis and planning, which eliminate escape strategies and problem avoidance.

Conclusions. Ontological security-insecurity manifests itself in different types of attachments and corresponding coping strategies. The results showed the importance of developing and adapting the methodology of ontological protection for Ukrainian socio-cultural realities. This technique is being prepared to be operationalised with the scales of psychological techniques used in this study.

Key words: ontological security, attachment theory, coping strategy, individual, adulthood

\section{INTRODUCTION}

Tn modern psychology, the attachment theory is one of the most popular areas Lof the study of close relationships, and it is of growing interest to researchers. The topic of human attachments is part of the issue of social relations between people, their regulation in the field of education, upbringing, and psychotherapy. Scholars considered the problem of human attachment as related to the ontological security of a person (Laing, 1960).

Ontological security is a general concept that characterises a person in the system of their close attachments. However, the lack of ontological security is manifested in the formation of dependent, anxious attachment, or in complete alienation from others. In his work, John Bowlby (1980) proved that from birth a person is inherent in a behavioural system of attachment, prompting to seek closeness with significant others in difficult moments of life. Researchers analysed current trends in the problem of partner buffering of attachment insecurity (Simpson \& Overall, 2014). With the advent of attachment-based psychotherapy, the attachment theory itself has been extended from American developmental psychology to clinical psychology and social psychology. Researchers conducted the study of the emerging of attachment features and functions in a specific sequence that begins with proximity-seeking, followed by safe haven, and finally secure base (Heffernan, Fraley, Vicary, \& Brumbaugh, 2012). In yet another study, adult attachment styles were examined (Fraley, Hudson, Heffernan, \& Segal, 2015). In foreign studies, the adult attachment style was described as a stable pattern of expectations, emotions and behaviours in relationships (Hazan \& Shaver, 1987); attachment styles were 
classified (Bartolomew \& Horowitz, 1991); as well as it was determined that any type of attachment can produce stress, if the relationship deteriorates and terminates (Simpson \& Overall, 2014). In the context of the topic of stress in relationships, the problems associated with the choice of effective coping strategies and the dependence of their type on the basic characteristics of attachment are of particular relevance.

\section{ATTACHMENT AS A NEED OF ONTOLOGICAL SECURITY}

The prosocial activity has great educational importance in the rationally organised social life, based on the laws and regulation of social behaviour and the development of both individuals and communities. Such social life of individuals ensures predictability, conflict-free and sustainable community and state as a whole. Educational tasks of organisation and regulation of social life are aimed to reduce the risks of disorganisation, playing a prevention role in the occurrence of social fears and supporting human ontological safety.

However, in a society, during its crisis periods (of economics, finances, war, forced resettlement of individuals, etc.), spontaneous processes characterised by certain instability and uncontrolled relations are always increasing. In fact, spontaneous processes, formation of volatility zones and common uncertainty in the society are threats to the ontological safety of people, and therefore an important problem of educational institutions. Ontological safety as a sense of security, is formed in the conditions of interaction of the individual with institutions (family, school, college, university, professional activity). Therefore, ontological safety is based on institutionality, on the system of status and roleplaying interactions between individuals. It is appropriate to distinguish microand macro-social levels at which ontological security may be weakened. At the microsocial level, such zones of volatility include crisis situations in social relations. At the macro-social level, it is appropriate to distinguish the factors that provoke the occurrence of uncertainty destroying the basis of ontological safety. Among them are group and intergroup conflicts, war, crisis phenomena in public life or the formalisation of social relations.

The microsocial level of ontological safety allows us to consider the educational and socio-psychological state of personal ontological security. Ontological security arises in conditions of openness, contact and clarity of the world for people. It exists inside everyday reality. An important condition for personal ontological safety is a trust in family members, parents, which has a psychological basis. On the basis of child's trust in the mother, a trust in the surrounding reality is forming. Development and changes in attachment of mother and child is a vital topic of research according to different social and cultural determinants (Khan et al., 2020). The absence of hostility and anxiety in relationships and personal interaction with social institutions is similar to the psychological child's trust in the mother. Sociological surveys show that the level of trust in the institutions 
of society correlates with the level of fear. The lower is trust in social centers, institutions or particular educational institutions, the higher is the level of anxiety and fear. Therefore, the integrity and wholeness of the modern person can be threatened by various alienated social relations, indifference, disrespect of educational social institutions to the personal and family problems and psychological crises (Hapon \& Vovk, 2020). This is how the society of disparate individuals is exposed. Such society has a number of problems, among which the educational problem of personal ontological insecurity and its overcoming has to be solved.

Only a harmonised self gives a person the sense of presence in the world as real, living, holistic, and continuous (in a timely sense). The outer (social) world, other people are experienced as equally real, continuous and holistic. In fact, this experience characterises an "ontologically secure person" (Laing, 1960, p. 67). The concept of "ontological security" (translation options: ontological confidence, ontological safety) was generally outlined by the English existential psychiatrist Laing as polar, different from the ontological insecurity of schizoids and schizophrenics, which constituted the subject of his study (Laing, 1960).

The existential position of security-insecurity corresponds to the degree of reliability of basic elements of being-in-the-world structuring: I (mental I and the body) and not-I (other people, the world). The outlined existential provisions are specified by another opposition to basic existential settings - embodied and unembodied self. The embodiment of mental I in the body as a physical object, the identification of one's own body (in time and space) continues the integrity of person in his life-in-the-world (this is the embodiment in the existential sense).

Instead, instability corresponds to alienation from self and others, and the splits of being in the world. Existential positions of confidence, incarnation, insecurity, find expression in ontological feelings that describe all the diversity of human experiences of themselves and the world. A sense of ontological security allows a person to face social, spiritual, and ethical difficulties and to welcome obstacles painlessly. Ontological security gives a person a sense of confidence in their reality and identity, as well as in the reality of the surrounding world and the identities of other people. Unlike attempts to individualise the concept of ontological insecurity, Laing revealed it as a pathological experience for the whole society, pointing to a certain responsibility of society for mental disorders (Laing, 1960).

The problem of codependence or counterdependence in a relationship is a marker of the loss of ontological security within a distorted communicative system of relationships with significant others. This problem acquires practical significance in the modern educational system and psychological practice, and it requires consideration of the functioning of distorted family systems and the psychological consequences of destructive communication and interaction. 


\section{ONTOLOGICAL SECURITY AND ITS CONNECTION WITH ATTACHMENTS AND CLOSE RELATIONSHIPS}

The study (Kopteva, 2013) examines ontological security in connection with various general psychological phenomena: self-attitude, experience, optimism-depression, self-actualisation, and meaning-making of the person. In the system of experiences of ontological security, the author singles out its basic level (i.e., close relationships, comfort, emotional attachment, values).

Psychologist Natalia Kopteva created her concept of types of ontological security and empirically investigated ontological security-insecurity using the author's methods (Kopteva, 2013). Her methods explore two levels of ontological security of a person: basic (i.e., experiencing close relationships, attachment) and the level of autonomy (i.e., separation from the world). The technique that investigates the basic level of ontological security is based on the principle of semantic differential. Another technique that examines the level of autonomy is psychometric. Kopteva cross-validated the construct of the "Ontological security" method and compared it with the classical personality factors of Raymond Cattell (Sixteen Personality Factor Questionnaire, 16 PF), as some of them (weakness of the Super-Ego, schizotinia, alienation, etc.) are associated with the theoretical justification of ontological uncertainty and indirectly - with the justification of ontological insecurity (Kopteva, 2013).

Attachment is a multilevel phenomenon that reflects the need for ontological security. Evolutionary, neurobiological, and socio-psychological factors are distinguished among those of attachment formation. Early attachment relationships form a personality with specific traits, attitudes, and ways of processing information.

According to Bowlby's theory, attachment is an attitude towards oneself and towards people that give (or do not give) a sense of security and safety (Bowlby, 1980). According to Patricia Crittenden, attachment is a strategy of behaviour first with significant others and then with everyone around (Crittenden, 2015, p. 57). Behaviour strategies are associated with the so-called "state of mind regarding attachment." A person receives the image of ontological security within the framework of their family's communication system through love, care, tenderness, and support.

In existing attachment models (Bartolomew \& Horowitz, 1991; Hazan \& Shaver, 1987), the key factors are intimacy avoidance and sensitivity to rejection; attitude to oneself and attitude to the other; behavioural systems of monitoring and regulation of attachment behaviour (Bartolomew \& Horowitz, 1991). In their study, Cindy Hazan and Phillip Shaver examined the attachment styles in detail and called them 'secure', 'anxious-ambivalent', and 'avoidant' (Hazan \& Shaver, 1987). According to the research results, attachment styles can be characterised using two independent parameters: anxiety and intimacy avoidance (Bartolomew \& Horowitz, 1991). In other studies, four types of attachment are distinguished: autonomy (type A) - acceptance of interdependence and self-sufficiency; overdependence (type B) - recognition of dependence and 
denial of independence; pseudoautonomy (type C) - rejection of interdependence and the supervalue of independence; disorientation (type D) - rejection of interdependence and self-sufficiency (Kazantseva, 2011), as well as four types of attitudes according to attachment styles: 1) autonomous - accepting interdependence; characterised by self-sufficiency, 2) overdependent - focusing on dependence; 3) pseudoautonomous - focusing on independence; 4) disoriented - characterised by rejection of both dependence and independence (Fedotov \& Rudakova, 2016).

Ukrainian authors Iryna Kuchmanych and Karina Sanko investigated the characteristics of the relationship between the attachment style and interrelationships in the marital subsystem, and found that most of the respondents had a reliable (secure) attachment style. Anxious style was peculiar to about a quarter of the respondents, and the smallest part of the respondents were people with avoidant and anxious-ambivalent attachment styles. The authors found that people with a positive outlook on themselves and others are more likely to respect the worldview, interests and opinions of their partners (Kuchmanych \& Sanko, 2013).

Thus, attachment can be viewed through the prism of dependence (as a degree of connection with other people) and independence (as an understanding of one's integrity and respect for others). Dependence and independence are inseparable characteristics of intimate relationships, and the subjective attitude towards dependence and independence is determined by the experience of previous relationships and culture. One of the main factors of relationship satisfaction is the attachment security, when intimacy and distance between partners are balanced.

\section{KEY COMPONENTS OF COPING BEHAVIOUR OF INDIVIDUALS WITH DIFFERENT ATTACHMENT STYLES}

From early childhood age, attachment is a necessary component of any interpersonal relationship; it arises from the need for ontological security and is established in the result of long-term interaction (Weiss, 1991). Each attachment style is characterised by a typical set of psychological defences and coping strategies. Researchers have found that the pattern of disorganised/ disoriented attachment style is directly related to the escape-avoidance coping strategy and, conversely, to a positive overestimation (Fedotov \& Rudakova, 2016).

The researchers concluded that high levels of tension relationships are reflected in the rigidity and inefficiency of coping strategies used. Betrayal is the most powerful stressor for a relationship (Ekimchik \& Sapyuz, 2016). Threats to marital relations are often associated with the feelings of jealousy, escalation of conflict, and domestic violence. Some authors propose to evaluate the situations related to jealousy depending on the real threat of the presence of a "third party" (Harris \& Darby, 2010). Reviews of studies on the relation- 
ship between infidelity and attachment styles show that infidelity in intimate relationships is more common in men with an avoidant and women with anxious attachments (Birnbaum, Reis, Mikulince, Gillath \& Orpaz, 2006; Harris \& Darby, 2010; Lazarus \& Folkman, 1988). These studies were mainly conducted with the participation of couples with the "dating" status. Given the differences in content and status between cohabitation and estrangement (LAT), the study found that individuals with anxious attachment are more prone to adultery, especially when the partner also has anxious attachment (Russell, Baker, \& McNulty, 2013). The limitation of capabilities and resources of an individual during the crisis periods of life and the peculiarities of life challenges can contribute to the use of emotion-focused coping strategies. Emotion-focused coping is recognised by scholars as the optimal way to solve relationship problems (Schoenmakers, van Tilburg, \& Fokkema, 2015).

Thus, there are groups of factors that determine the dynamics of close relationships. An important role is played by the manifestation of the subjectivity and individuality of partners, their attachment style, as well as the degree of adaptive behaviour of coping with stress, which also affects the development of relationships and the degree of their comfort for partners. Our empirical study analysed the characteristics of close relationships in early and middle adulthood and the differences in coping strategies in individuals with different attachment styles, as well as the relationship between attachment styles and coping strategies.

\section{EMPIRICAL STUDY OF INDIVIDUAL TYPES OF ATTACHMENT AS MARKERS OF ONTOLOGICAL SECURITY-INSECURITY}

The study group consisted of 90 persons: 45 male and 45 female, at the age of early and middle adulthood. The Questionnaire of Attachment to Close People and the survey by Natalia Sabelnikova and Dmitriy Kashirsky (Sabelnikova \& Kashirsky, 2015), Richard Lazarus and Susan Folkman's Ways of Coping Questionnaire (Lazarus \& Folkman, 1988), The Coping Strategy Indicator (CSI) by James Amirkhan (Amirkhan, 1990), Relationship Questionnaire (RQ) by Kim Bartholomew and Leonard Horowitz (Bartolomew \& Horowitz, 1991) adapted by Tatyana Kazantseva (Kazantseva, 2011), and Freiburg Personality Inventory (Fahrenberg, Hampel, \& Selg, 2010) were used in the study. For completion the tasks of the research, such statistical methods as comparative analysis (using the nonparametric Mann-Whitney test) and correlation analysis were used.

People from the study group were from 20 to 42 years old. Group of the study consisted of 19 women and 20 men in age from 20 to 25 years, 12 women and 11 men in age from 26 to 30 years, 5 women and 7 men in age from 31 to 36 years and 9 women and 7 men from 36 to 42 years old. These were the persons in age of early and middle adulthood getting their second higher educational degree, students of the last years and persons who already have higher education. Such a group of people because they already have 
experience of close relationship, so, they can analyse it from the point of view of its difficulties and their attachment to another person.

According to the results of The Questionnaire of Attachment to Close People, among the subjects, the type of attachment prevails, in which the avoidance mechanism dominates: on the avoidance scale, the indicator is 76.71 , and on the anxiety scale, it is 61.68 .

According to The Relationship Questionnaire by Bartholomew (Bartholomew \& Horowitz, 1991), the ratio of the number of respondents with different attachment styles is shown in Fig. 1.

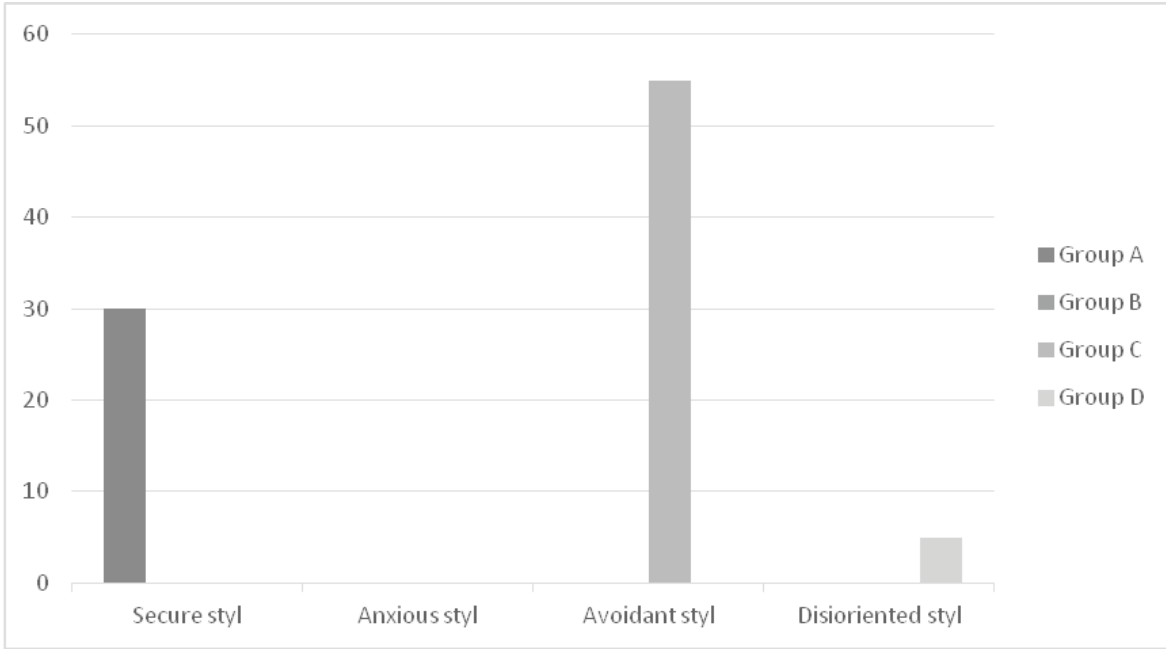

Fig. 1. The number of subjects in groups A, B, C, D with different attachment styles based on the results of the relationship questionnaire (Bartholomew \& Horowitz, 1991) (Group A, n = 30; Group B, n = 0; Group C, n = 55; Group D, n = 5).

In group C 'Avoidant (detached)' 55 people need more time to get closer to another person, more personal space, they often perceive the attachment of others as a threat. 30 respondents have a secure (reliable) attachment style (A): they are open, not afraid to be loving and sincere with a partner. Secure attachment is associated with the absence of contradictions in the behaviour of significant others, in richness of their emotional repertoire of reactions, and the quality of feedback from the wider social environment.

According to The Questionnaire by Sabelnikova and Kashirsky (2015), it was found that $3 \%$ of respondents have no relationship, for $22 \%$ the relationship can hardly be called intimate, $23 \%$ - the relationship lasts less than 6 months, $27 \%$ - it lasts more than 6 months, but less than a year, $8 \%$ - the relationship lasts $1-2$ years, $12 \%$ - from 2 to 5 years, and 5\% - more than 5 years. On the scale of satisfaction with relationships, it was found that $3 \%$ of respondents did not have relationships, 52\% were completely satisfied with the relationship, 20\% were generally satisfied, $7 \%$ were rather satisfied than not satisfied, 
$3 \%$ were satisfied by about $50 \%, 3 \%$ - rather not satisfied than satisfied, $2 \%$ had little satisfaction, $10 \%$ were not satisfied at all. On the scale of duration of close relations in the past, it was found that $3 \%$ had no close relationship with anyone, 25\% - the relationship lasted less than 6 months, 33\% - from 6 months to 1 year, $9 \%-1-2$ years, $21 \%-2-5$ years and in $9 \%$ of the subjects - more than 5 years. On the scale of satisfaction with previous relationships, it was found that $4 \%$ did not have close relationships, $71 \%$ of the respondents were completely satisfied with the relationship, $11 \%$ were generally satisfied, $2 \%$ were rather satisfied than not satisfied, 3\% were satisfied by about $50 \%, 6 \%$ were rather not satisfied than satisfied, $2 \%$ were not satisfied enough, $1 \%$ were completely dissatisfied. Interestingly, for a third of the respondents, the longest intimate relationships lasted from six months to a year, and according to the self-analysis of the previous experience of close relationships, $71 \%$ of the respondents were completely satisfied with them.

Based on the results of The Questionnaire of attachment to close people by Sabelnikova and Kashirsky (Sabelnikova \& Kashirsky, 2015), two subgroups were formed: the avoidance subgroup (73 persons) and the anxiety subgroup (17 persons). Comparative analysis using the nonparametric Mann-Whitney test between these groups revealed differences in indicators of confrontive coping and irritability. Confrontive coping is more common in avoidanceprone individuals (Rank Sum1 $=3117.5$, Rank Sum2 $=977.5, Z=-2.1, \mathrm{p} \leq$ 0.05). Confrontation, persistence in defending one's own interests, is seen as a maladaptive tactic that does not contribute to the development of attachment in a relationship. Irritability can take the form of a defensive reaction when confronted with an uncomfortable and frightening reality, and it is inherent in avoidant individuals (Rank Sum1 $=3585.5$, Rank Sum2 $=509.5, Z=2.7$, p $\leq 0.01)$.

Due to the small number of types B and D, comparison of subjects by type of attachment according to The Relationship Questionnaire by Bartholomew and Horowitz (Bartolomew \& Horowitz, 1991) was carried out between type A 'secure' (30 persons) and type C 'avoidant' (55 persons) using the nonparametric Mann-Whitney test. Differences in the indicators of distancing coping strategy and extraversion were found between the groups, which are higher for persons with avoidant attachment style. They tend to emotionally distance themselves from the problem and the partner, reducing the subjective significance of the situation and their own experiences (Rank Sum1 $=2661$, Rank Sum2 = 994, $Z=2.7, \mathrm{p} \leq 0,01)$; however, they can exhibit significant communicative activity, which is a paradoxical form of avoidance of intimacy (Rank Sum1 = 2585, Rank Sum2 = 1070, Z = 2.1, p $\leq 0.05$ ).

According to the results of the correlation analysis, the indicator of avoidance is directly related to confrontive coping $(r=-0.34, p \leq 0.01)$. Persons inclined to avoidance prefer a strategy of confrontive coping, impulsive, not always purposeful concrete actions aimed at changing the situation and the expression of negative emotions, which may be accompanied by manifestations of hostility and conflict, difficulties in planning and predicting the 
outcome of behaviour. The indicator of anxiety is directly correlated with coping strategies of seeking social support $(\mathrm{r}=0.53, \mathrm{p} \leq 0.01)$ and positive reappraisal $(\mathrm{r}=0.47, \mathrm{p} \leq 0.01)$, and inversely related to planful problemsolving strategy $(r=-0.57, p \leq 0.01)$. The deficit of the planning function for solving problems is more typical of persons who are inclined to worry about relationships, overestimate the importance of their partner, overly rely on them in solving problem situations and underestimate their own resources and abilities for solving them, which contributes to the formation of dependence in relationships. The fear of losing significant relationships prompts the search for social, informational, emotional and effective support, which increases the amount of external resources; however, supports the formation of a dependent attitude and excessive expectations towards others. It is also more common for people with anxious attachment to overcome negative feelings through philosophical and positive rethinking of a problem, considering it in the context of self-development, which can lead to an underestimation of the possibilities of its effective solution and shifting responsibility onto others.

The indicator of secure attachment style is directly related to coping strategies of self-controlling $(\mathrm{r}=0.42, \mathrm{p} \leq 0.01)$, accepting responsibility $(\mathrm{r}=0.47, \mathrm{p} \leq 0.01)$, planful problem-solving $(\mathrm{r}=0.53, \mathrm{p} \leq 0.01)$, and is inversely related to coping strategies of escape $(r=-0.47, p \leq 0.01)$ and distancing $(\mathrm{r}=-0.55, \mathrm{p} \leq 0.01)$. There are also direct correlations between the indicator of avoidant attachment type with self-controlling $(r=0.51$, $p \leq 0.01)$, positive reappraisal $(r=0.42, p \leq 0.01)$, escape $(r=0.45, p \leq 0.01)$, distancing $(r=0.57, \mathrm{p} \leq 0.01)$, and the reverse - with the seeking social support strategy $(\mathrm{r}=-0.43, \mathrm{p} \leq 0.01)$.

Secure attachment type is based on mutual trust and responsibility, which excludes strategies of escape and problem avoidance, impulsive actions, emotional withdrawal and devaluation of the problem. Individuals with secure attachment take control of their own emotions and focus on analysing the problem and planning ways to solve it, taking into account objective conditions, past experience, and available resources. Avoidant individuals are less likely to seek help and support from the social environment due to a lack of trust in external resources. Instead, they use a wide range of passive ways to reduce emotional stress by suppressing emotions, rationalising and intellectualising, distracting, ignoring and devaluing a problem situation and their own experiences associated with it, which does not contribute to its solution and leads to further complications.

Thus, the attachment patterns very clearly manifest themselves in ways of overcoming stress and in attitudes to problem situations; they determine the degree of activity and adaptability of coping strategies and, accordingly, allow predicting the degree of resilience (stress tolerance) of an individual.

\section{CONCLUSION}


Kopteva's psychological empirical studies have shown close direct correlations between a person's ontological security and happiness, attachment in relationships, outsympathy, self-interest, etc. At the same time, the link between insecurity and depression has been shown (Kopteva, 2013). All this indicates that ontological security is global in nature and is closely related to a wide range of different phenomena of psychological well-being.

Attachment is a multilevel phenomenon, it can be considered as a kind of interpersonal expectations and attitudes based on the needs for ontological security and affiliation. Individual differences in attachment are manifested in the perception of oneself and other people, sensitivity to rejection and avoidance of intimacy, monitoring and regulation of one's behaviour in relationships. One of the main factors of relationship satisfaction is the ability to strike a healthy balance between intimacy and distance, which is not fundamentally available to those prone to anxiety and avoidance in relationships, emotional codependence and counterdependence.

Individuals with an anxious attachment style are characterised by insufficient independence, excessive expectations for solving problems addressed to others, dependence on external support, intellectualisation and rationalisation, a deficit in the planning function, and shifting responsibility onto others. Persons with an avoidant attachment style in problematic situations are characterised by impulsiveness, defensive and protest behaviour and various passive ways to reduce emotional stress, namely: devaluating the problem and their own experiences, suppressing emotions, distracting, rationalising, intellectualising, and ignoring the problem. They also have difficulty finding external resources to solve problems and relying on existing social resources due to mistrust and fear of dependence. The skills and abilities to actively and constructively overcome problem situations (controlling one's emotions, planning a solution to the problem) are associated with a reliable (secure) attachment style and contribute to the construction of harmonious relationships.

Psychoeducation, psychocorrection, development of personal resourcefulness in overcoming stress will promote the formation of resilience, stress resistance, more active and adaptive coping strategies, which in turn will increase the resourcefulness of interpersonal relationships and contribute to the accumulation of experience of safe intimacy. It will also help reduce anxiety and propensity to avoidance behaviour as well as correct attitudes associated with adverse early emotional experiences gained in close relationships with significant others.

\section{RESEARCH PROSPECTS}

The prospect of our study is the adaptation of a comprehensive methodology of ontological security to the Ukrainian socio-cultural conditions and further research on the chronotype of ontological security in connection with the dynamics of relationships and attachments between people, especially in the 
family. There is a need to find out what types of attachments correspond to the ontological security-insecurity of individuals and partners. There is a need to create a separate method of diagnosis of ontological security-insecurity and its operationalisation.

The research can be continued in the study of psychological patterns of attachment, further study of their cognitive, emotional and behavioural components. Questions remain open concerning the ability of a person in adulthood to consciously correct their attachment patterns, as well as the possible prospects for change in relationships that do not satisfy partners. The results of such studies can become the basis for providing psychological assistance in order to increase psychological resourcefulness, form a proactive and constructive approach to life of the individual, harmonise the psychological state of mind of partners, develop interpersonal relationships and enhance ontological security.

\section{REFERENCES}

[1] Amirkhan, J. H. (1990). A factor analytically derived measure of coping: The Coping Strategy Indicator. Journal of Personality and Social Psychology, 59(5), 1066-1074. doi: 10.1037/0022-3514.59.5.1066

[2] Bartolomew, K., \& Horowitz, L. M. (1991). Attachment styles among bung adults a test of a four-category model. Journal of Personality and Social Psychology, 61(2), 226-244.

[3] Birnbaum, G. E., Reis, H. T., Mikulincer, M., Gillath, O., \& Orpaz, A. (2006). When sex is more han just sex: Attachment orientations, sexual experience, and relationship quality. Journal of Personality and Social Psychology, 9, 929-943.

[4] Bowlby, J. (1980). Attachment and loss, vol. 3: Loss, sadness and depression. New York: Basic Books.

[5] Crittenden, P. M. (2015). Raising parents: Attachment, Parenting and Child Safety (2 ${ }^{\text {nd }}$ ed.). London: Routledge.

[6] Khan, F., Chong, J. Y., Theisen, J. C., Fraley, R. C., Young, J. F., \& Hankin, B. L. (2020). Development and change in attachment: A multiwave assessment of attachment and its correlates across childhood and adolescence. Journal of Personality and Social Psychology, 118(6), 1188-1206.

[7] Ekimchyk, O. А., Sapyuz, А. А. (2016). Повседневные трудности в близких отношениях мужчины и женщины [Everyday difficulties in close relationship of men and women]. In: T. L. Kryukova (Ed.), Psychology of stress and coping behaviour: Resources, health, development: Materials of the IV Intern. Scientific. Conf., 22-24 Sept. 2016: in 2 volumes. (pp. 45-48). Kostroma: Издательство Костромского государственного университета.

[8] Fedotov, I. A, Rudakova, D. A. (2016). Психологические защиты и копинг у людей с различными типами привязанности [Psychological security and coping in people with different types of attachment]. Personality in a Changing World: Health, Adaptation, Development: Online Journal, 13, 85-97. Retrieved from https://humjournal.rzgmu.ru/uploadfiles/02_13_16/09_2_13.pdf

[9] Fahrberg, J., Hampel, R., \& Selg, H. (2010). Freiburger Persönlichkeitsinventar FPI-R. [Freiburg personality inventory FPI-R]. Primary data of the normalisation sample 1982. (Version 1.0.0) [data and documentation]. Trier: Forschungsdatenzentrum des Leibniz Institut für Psychologie ZPID. doi.org/10.5160/psychdata.fgjn82fr19

[10] Fraley, R. C., Hudson, N. W., Heffernan, M. E., \& Segal, N. (2015). Are adult attachment styles categorical or dimensional? A taxometric analysis of general and relationshipspecific attachment orientations. Journal of Personality and Social Psychology, 109(2), 354-368. doi:10.1037/pspp0000027 
[11] Hapon, N. P., \& Vovk, A. O. (2020). Codependency in family systems with distorted communication patterns and their manifestation in an individual's social. In: N. P. Hapon, S. L. Hrabovska, N. V. Hrebin., et al. (Eds.), Personality in society: Psychological mechanisms of activity; collective monograph (pp. 1-16). Lviv-Torun: Liha-Pres. doi:10.36059/978-966-397-209-1/1-16

[12] Harris, C., \& Darby, R. (2010). Jealousy in adulthood. In: S. L. Hart \& M. Legerstee (Eds.), Handbook of jealousy: Theory, research, and multidisciplinary approaches (pp. 547-571). Oxford: Blackwell Publishing Ltd.

[13] Hazan, C., \& Shaver, P. R. (1987). Romantic love conceptualized as an attachment process. Journal of Personality and Social Psychology, 52(3), 511-524. doi: 10.1037/0022-3514.52.3.511

[14] Heffernan, M. E., Fraley, R. C., Vicary, A. M., \& Brumbaugh, C. C. (2012). Attachment features and functions in romantic relationships. Journal of Social and Personal Relationships, 29, 671-693.

[15] Kazantseva, T. V. (2011). Социально-психологические детерминанты межличностной привязанности. Диссертаиия на соискание ученой степени кандидата психологических наук по специальности 17.00.06 - Социальная психология [Socio-psychological determinants of interpersonal attachment. Thesis for the acquisition of a scientific degree of Candidate of Psychological Sciences in the specialty 17.00.06 - Social Psychology]. Saint Petersburg: Издательство Санкт-Петербургского государственного университета.

[16] Khan, F., Chong, J. Y., Theisen, J. C., Fraley, R. C., Young, J. F., \& Hankin, B. L. (2020). Development and change in attachment: A multiwave assessment of attachment and its correlates across childhood and adolescence, Journal of Personality and Social Psychology, 118(6), 1188-1206.

[17] Kopteva, N. V. (2013). Онтологическая уверенность: понятие и операционализация. Диссертация на соискание ученой степени доктора психологических наук по специальности 19.00.01 - Общая психология, психология личности, история психологии [Ontological security: Concept and operationalisation. Thesis for the acquisition of a scientific degree of Doctor of Psychological Sciences in the specialty 19.00.01 - General Psychology, Personality Psychology, History of Psychology]. Ekaterinburg: Уральский федеральный университет, from https:/ /elar.urfu.ru/bitstream/10995/5025/2/urgu1188s.pdf

[18] Kopteva, N. V., \& Kalugin, A. Y. (2015). Revisiting the values which correspond to the ontological security. Biosciences Biotechnology Research Asia, April, 815-822. doi: 10.13005/bbra/1727

[19] Kuchmanych, I. M., \& Sanko, K. О. (2013). Особливості взаємозв'язку типу прив' язаності та взаємостосунків у подружній підсистемі [Ресuliarities of the relationship between the type of attachment and the relationship in the marital subsystem]. Scientific Bulletin of the Mykolaiy State University V.O. Sukhomlynsky. Series: Psychological Sciences, 2(11), 167-170. Retrieved from http://nbuv.gov.ua/UJRN/Nvmdups_2013_2_11_31

[20] Laing, R. D. (1960). The divided self: An existential study in sanity and madness. Harmondsworth: Penguin.

[21] Lazarus, R., \& Folkman, S. (1988). Manual for ways of coping questionnaire, Palo Alto, CA: Consulting Psychologists Press.

[22] Russell, M., Baker, L. R., \& McNulty, J. K. (2013). Attachment insecurity and infidelity in marriage: Do studies of dating relationships really inform us about marriage? Journal of Family Psychology, 27, 242-251. doi: 10.1037/a0032118

[23] Sabelnikova, N. B., \& Kashirsky, D. V. (2015). Опросник привязанности к близким людям [The questionnaire of attachment to close people]. Psychological Journal, 36(4), 84-97.

[24] Schoenmakers, E. C., van Tilburg, T. G., \& Fokkema, T. (2015). Problem-focused and emotionfocused coping options and loneliness: How are they related? European Journal of Ageing, 12, 153-161. doi: 10.1007/s10433-015-0336-1

[25] Simpson, J. A., \& Overall, N. C. (2014). Partner buffering of attachment insecurity. Current Directions in Psychological Science, 23, 54-59. doi:10.1177/0963721413510933

[26] Weiss, R. S. (1991) The attachment bond in childhood and adulthood. In C. M. Parke \& J. Stevenson-Hinde (Eds.), Attachment across the life cycle (pp. 171-184). London: Routledge. 